Vol. 1 No.1 ; November 2014

\title{
EFEKTIFITAS AIR KELAPA FERMENTASI SEBAGAI LARUTAN PENGHEMAT HERBISIDA KOMERSIL
}

\author{
*SETIADI KURNIAWAN ${ }^{1}$, YUYUN KURNIAWATI ${ }^{1}$, DWI SANDRI ${ }^{2}$, FATIMAH $^{2}$ \\ ${ }^{I}$ Mahasiswa Pengajar Jurusan Teknologi Industri Pertanian, Politeknik Negeri Tanah Laut, Jl. A. \\ Yani, Km 6, Ds. Panggung, kec. Pelaihari, kab Tanah Laut, Kalimantan Selatan \\ ${ }^{1}$ Staff Pengajar Jurusan Teknologi Industri Pertanian, Politeknik Negeri Tanah Laut, Jl. A. Yani, \\ Km 6, Ds. Panggung, kec. Pelaihari, kab Tanah Laut, Kalimantan Selatan
}

Naskah diterima : 7 Oktober 2014; Naskah disetujui : 24 November 2014

\begin{abstract}
ABSTRAK
Herbisida merupakan salah satu penyebab pencemaran lingkungan terutama pencemaran tanah dan air. Selain menyebabkan pencemaran lingkungan, harga herbisida relatif mahal sehingga banyak dikeluhkan oleh masyarakat. Penelitian ini bertujuan untuk menemukan formulasi herbisida jenis baru dengan harga yang ekonomis. Penelitian dilakukan dengan cara memfermentasi air kelapa dengan menggunakan ragi tape (1.5\%, 5 \%,dan $10 \%$ selama 6 hari. Penyemprotan dilakukan dengan mengencerkan sampel. Aplikasi lapangan dilakukan pada plot berukuran $50 \mathrm{~cm} \times 50 \mathrm{~cm}$ sebanyak 3 kali pengulangan. Setelah 14 hari penyemprotan dilakukan penghitungan presentase mortalitas gulma pada setiap plot. Hasil pengamatan menunjukan sampel dengan konsentrasi ragi $5 \%$ memiliki tingkat mortalitas 93\%, sedangkan herbisida memiliki tingkat mortalitas $97 \%$. Herbisida jenis baru ini efektif terhadap gulma berdaun sempit.
\end{abstract}

Kata kunci : Herbisida, air kelapa, Ragi Tape, Inkubasi, mortalitas.

\section{PENDAHULUAN}

Herbisida merupakan senyawa kimia yang dipergunakan untuk menghambat pertumbuhan atau mematikan tumbuhan (gulma). Herbisida dapat mempengaruhi satu atau lebih proses - proses (seperti pada proses pembelahan sel, perkembangan jaringan, pembentukan klorofil, fotosintesis, respirasi, metabolisme nitrogen, aktivitas enzim dan sebagainya) yang sangat diperlukan tumbuhan untuk mempertahankan kelangsungan hidupnya. Herbisida berasal dari metabolit, hasil ekstraksi, atau bagian dari suatu organisme. Herbisida merupakan senyawa kimia peracun gulma yang dapat menghambat pertumbuhan bahkan mematikan tumbuhan tersebut (Riadi, 2011).

Herbisida masih banyak digunakan oleh masyarakat di Indonesia untuk memberantas gulma. Herbisida merupakan salah satu penyebab pencemaran lingkungan terutama pencemaran tanah dan air. Selain menyebabkan pencemaran lingkungan, harga herbisida relatif mahal sehingga banyak dikeluhkan oleh masyarakat. Masyarakat tidak memiliki pilihan selain mempergunakan herbisida karena mereka membutuhkan penanganan cepat terhadap gulma tanpa memikirkan dampak negatif yang ditimbulkan oleh herbisida tersebut.

*Korespondensi : 
Air kelapa memiliki pH yaitu 5,6 (Palungkun, 1992). Adanya asam-asam organik dan anorganik dalam air kelapa menyebabkan $\mathrm{pH}$ air kelapa rendah. Asam-asam yang terdapat pada air kelapa antara lain asam amino, asam-asam non volatil, asam nukleat, asam shikinat dan asam kuinat (Tuleckle, 1961). Berdasarkan penelitian Balai Penelitian Tanaman Rempah dan Obat (2012), asam asetat (termasuk asam asetat alami) dapat digunakan sebagi bahan dasar dalam pembuatan formula herbisida.

Dalam usaha mengurangi penggunaan herbisida, berbagai penelitian terus dilakukan. Salah satu ide yang penulis miliki yaitu mempergunakan air kelapa yang belum termanfaatkan secara optimal sebagai bahan penghemat herbisida. Penelitian ini mempergunakan air kelapa fermentasi sebagai larutan yang akan ditambahkan pada herbisida dengan tujuan mendapatkan herbisida jenis baru.

\section{BAHAN DAN METODE}

Bahan yang digunakan antara lain air kelapa, Herbisida (Merek "Kleen up") kandungan bahan aktif isopropil amina glifosat $480 \mathrm{~g} / \mathrm{l}$ (setara glifosat $356 \mathrm{~g} / \mathrm{l}$ ), ragi tape, aquades, dan air tanpa klorin.

\section{Pembuatan sampel}

Pembuatan sampel dilakukan dengan memfermentasikan $100 \mathrm{~mL}$ air kelapa dengan ragi tape (konsentrasi ragi 1,5\%, $5 \%$ dan $10 \%$ ) selama 6 hari. Air kelapa hasil fermentasi kemudian ditambahkan herbisida sebanyak $29 \%$. Setelah ditambahkan herbisida, sampel akan diinkubasi selama 8 hari sebelum dilakukan aplikasi lapangan.

\section{Pembuatan Kontrol 1}

Pembuatan kontrol 1 dilakukan dengan cara mengencerkan $40 \mathrm{~mL}$ herbisida dalam $100 \mathrm{~mL}$ air. Dari pengenceran tersebut diambil sebanyak $10 \mathrm{~mL}$ yang akan diencerkan kembali dalam $750 \mathrm{~mL}$ air sebelum dilakukan aplikasi lapangan.

\section{Pembuatan Kontrol 2}

Pembuatan kontrol 2 dilakukan dengan mengencerkan $10 \mathrm{~mL}$ herbisida dalam 750 $\mathrm{mL}$ air. Kemudian siap dilakukan aplikasi lapangan 


\section{Aplikasi Lapangan}

Aplikasi lapangan dilakukan dengan cara melarutkan masing - masing $10 \mathrm{~mL}$ sampel dalam $750 \mathrm{~mL}$ air pada hand sprayer. Aplikasi lapangan dilakukan pada plot berukuran $50 \mathrm{~cm}$ x $50 \mathrm{~cm}$ dengan vegetasi tertentu. Penyemprotan dilakukan sebanyak 3 kali pengulangan pada masing - masing sampel. Data awal yang harus dicatat sebelum aplikasi lapangan dilakukan yaitu jumlah rumput yang terdapat pada masing - masing plot agar mempermudah perhitungan mortalitas. Perhitungan mortalitas dilakukan dengan rumus sebagai berikut :

$$
\text { Mortalitas }=\frac{\text { Rata-rata jumlah rumput uji-jumlah rumput yang bertahan hidup }}{\text { Rata-rata jumlah rumputuji }} \times 100 \%
$$

\section{HASIL DAN PEMBAHASAN}

Harga 1 liter herbisida dengan merek "Kleen up" mencapai Rp 52.000. Bagi para petani bermodal kecil, harga tersebut tergolong mahal. Mahalnya herbisida mendorong petani berpikir kreatif untuk menghemat biaya pembelian herbisida yaitu dengan cara mencampurkan air kelapa dan ragi tape kedalam herbisida agar volume herbisida menjadi lebih banyak.

Dalam penelitian ini, $\mathrm{pH}$ sampel merupakan salah satu parameter yang menjadi bahan pengamatan dalam 10 hari (Tabel 1). Air kelapa tanpa ragi memiliki pH yang lebih rendah jika dibandingkan air kelapa dengan penambahan ragi. Hal tersebut mungkin terjadi karena tidak ada pemecahan glukosa menjadi etanol sehingga $\mathrm{pH}$ sampel tidak sama dengan $\mathrm{pH}$ sampel dengan penambahan ragi tape. Dalam air, etanol memiliki $\mathrm{pH}$ hampir netral. $100 \%$ etanol memiliki pH 7.33 (Anonim, 2013). Apabila pH sampel yang mengandung etanol dengan $\mathrm{pH}$ tertentu (sesuai dengan kadar etanol yang dikandung) dapat dipastikan $\mathrm{pH}$ sampel menjadi lebih tinggi.

Herbisida yang digunakan dalam penelitian ini mengandung bahan aktif isopropil amina glifosat $480 \mathrm{~g} / \mathrm{l}$ (setara glifosat $356 \mathrm{~g} / \mathrm{l}$ ) dengan merek "Kleenup”. Kleenup merupakan herbisida purna tumbuh yang bersifat sistemik berbentuk larutan dalam air berwarna coklat muda untuk mengendalikan alang-alang pada pertanaman karet, kelapa sawit, lahan tanpa tanaman serta gulma berdaun sempit pada tanaman teh. 
Tabel 1. Pengukuran $\mathrm{pH}$ sampel fermentasi

\begin{tabular}{llllllll}
\hline \multirow{2}{*}{ Sampel } & \multicolumn{2}{l}{ pH sampel } & & & & \\
& Hari & Hari & Hari & Hari & Keterangan & \\
& ke-0 & ke-2 & ke-3 & ke-4 & & & \\
\hline A & 5.5 & 3.6 & 3.5 & 3.5 & & & \\
B & 5.5 & 4.3 & 4.1 & 4 & & & \\
C & 5.5 & 3.8 & 3.6 & 3.9 & Pada hari ke 6 hasil fermentasi \\
D & 5.5 & 3.7 & 3.5 & 3.8 & dicampurkan dangan herbisida (C, D, dan \\
E & 5.5 & 3.7 & 3.5 & 3.7 & E) & \\
\hline
\end{tabular}

Keterangan :
A : Air Kelapa
B : Air Kelapa + Herbisida
$\mathrm{C}:$ Air Kelapa + ragi tape 1,5 g + Herbisida
D : Air Kelapa + ragi tape $5 \mathrm{~g}+$ Herbisida
E : Air Kelapa + ragi tape $10 \mathrm{~g}+$ Herbisida

Aplikasi lapangan dilakukan pada lahan plasma kelapa sawit di desa Panggung Kecamatan Pelaihari yang berusia 4 tahun (Tanaman Menghasilkan Tahun Pertama). Tanaman kelapa sawit pada usia ini membutuhkan perawatan khusus agar menunjang pertumbuhan tanaman. Perawatan yang sering dilakukan yaitu membersihkan gulma yang terdapat di sekitar pohon kelapa sawit dengan cara penebasan dan semprot. Perawatan tanaman ini bertujuan agar mempermudah pemanenan buah dan pemupukan. Gulma yang terdapat disekitaran lahan penelitian didominasi oleh rumput Kerbau (Paspulum conjugatum). Gulma jenis ini merambat pada bagian bawah tanaman kelapa sawit sehingga akan mempersulit pemanenan maupun pemupukan kelapa sawit sehingga rumput kerbau harus dibasmi. Pengamatan pasca aplikasi lapangan merupakan upaya untuk memperoleh data mengenai keefektifan sampel uji Selama 14 hari pengamatan (Tabel 2).

Pada Tabel 2 dapat diketahui bahwa hasil terbaik ditunjukan pada sampel D yaitu mortalitas mencapai 93\%. Hal tersebut menunjukan hasil terbaik karena ketersediaan unsur hara dan mikroorganisme seimbang sehingga mikroorganisme dapat menguraikan unsur hara dengan sempurna. Sampel $C$ dan E juga menunjukan hasil efektif namun tidak seefektif sampel D. Perbedaan keefektifan ini disebabkan oleh perbedaan pada konsentrasi ragi yang digunakan pada tiap-tiap sampel. 
Tabel 2. Data Mortalitas Gulma rumput Kerbau (Paspulum conjugatum)

\begin{tabular}{llllll}
\hline \multirow{2}{*}{ Sampel } & Konsentrasi & \multicolumn{2}{l}{ Mortalitas (\%) } & & \\
\cline { 3 - 5 } & Herbisda (\%) & Plot I & Plot II & Plot III & Rataan \\
\hline $\mathrm{A}$ & 0 & 0 & 0 & 0 & 0 \\
$\mathrm{~B}$ & 0.38 & 73 & 67 & 66 & 68 \\
$\mathrm{C}$ & 0.38 & 67 & 65 & 72 & 68 \\
$\mathrm{D}$ & 0.38 & 95 & 94 & 91 & 93 \\
$\mathrm{E}$ & 0.38 & 73 & 71 & 70 & 71 \\
Kontrol 1 & 0.38 & 82 & 86 & 90 & 86 \\
Kontrol 2 & 1.31 & 98 & 97 & 96 & 97 \\
\hline
\end{tabular}

Menurut Riadi (2011), herbisida dibedakan berdasarkan jenis senyawa organik. Salah satu senyawa organik tersebut adalah glifosat. Glifosat merupakan suatu herbisida yang bersifat non-selektif yang diserap oleh daun yang di angkut perlahan-lahan ke seluruh bagian tumbuhan. Glifosat efektif dalam membunuh berbagai tanaman, termasuk rumput berdaun lebar dan tanaman berkayu. Pengamatan lain menunjukan bahwa terdapat beberapa gulma yang resisten (kebal) terhadap sampel yaitu jenis rumput babandotan dan perdu (karamunting) setelah 14 hari aplikasi lapangan dilakukan.

Kombinasi herbisida komersil dengan air kelapa fermentasi pada sampel D efektif dalam memberantas gulma dengan nilai mortalitas terbaik yaitu 93\%. Tetapi kombinasi ini mengubah sifat herbisida komersil menjadi selektif, hanya dapat membasmi gulma berdaun sempit.

\section{UCAPAN TERIMA KASIH}

kami mengucapkan terima kasih kepada petani pemilik kebun plasma kelapa sawit di desa Panggung Kecamatan Pelaihari yang telah bersedia menjadi tempat percobaan aplikasi herbisida.

\section{DAFTAR PUSTAKA}

Anonim. 2013. "Ethanol" <URL : id.m.wikipedia.org/wiki/etanol, April, 2013.

Palungkun, R. 1992. Aneka Produk Olahan Kelapa. Jakarta: Penebar Swadaya.

Riadi, M, 2011. Herbisida dan Aplikasinya. Progam Studi Agoteknologi, jurusan Budidaya Pertanian, Fakultas Pertanian. Universitas Hasanuddin.

Tuleckle. 1961. Coconut. Longmans Geen and. Co., London. 